\title{
Optimal capacitor placement in a distribution system using ETAP software
}

\author{
M. J. Tahir ${ }^{1}$, Badri. A. Bakar ${ }^{2}$, M. Alam ${ }^{3}$, M. S. Mazlihum ${ }^{4}$ \\ ${ }^{1,2}$ Universiti Kuala Lumpur-BMI, Malaysia \\ ${ }^{1}$ The University of Lahore, Pakistan \\ ${ }^{3}$ ILMA University, Pakistan \\ ${ }^{4}$ Universiti Kuala Lumpur, Malaysia
}

\begin{tabular}{l}
\hline \hline Article Info \\
\hline Article history: \\
Received Oct 12, 2018 \\
Revised Feb 5, 2019 \\
Accepted Feb 24, 2019 \\
\hline
\end{tabular}

Keywords:

Distribution system

ETAP

GA

OCP

\begin{abstract}
Mostly loads are inductive in nature in content of distribution side for any power system. Due to which system faces high power losses, voltage drop and reduction in system power factor. Capacitor placement is a common method to improve these factors. To maximize the reduction of inductive load impact, optimal capacitor placement (OCP) is necessary with the objective function of system cost minimization for voltage profile enhancement, power factor improvement and power losses minimization. As OCP is a non-linear problem with equality and inequality limitations, so the stated objective depends upon he placement and sizes of the capacitor banks. Electrical transient analyzer program (ETAP) software is used for the evaluation and modelling the power systems and genetic algorithm (GA) is used as an optimization technique for the minimization of the objective function. In this paper, to show the effectiveness of the technique IEEE 4bus, 33 bus system and NTDC $220 \mathrm{KV}$ real time grid system is modelled and evaluated in terms of objective minimization i-e maximum cost saving of the power system.
\end{abstract}

Copyright $\odot 2019$ Institute of Advanced Engineering and Science. All rights reserved.

\section{Corresponding Author:}

Badri. A. Bakar,

Department of Electrical Technology,

Universiti Kuala Lumpur, British Malaysian Institute,

Batu 8, Jalan Sungai Pusu, 53100 Gombak, Selangor, Malaysia.

Email: badri@unikl.edu.my

\section{INTRODUCTION}

Normally in any power system, power generated on source side and delivered towards load side for the consumption through distribution system. Mostly loads are divided into two types i-e industrial and domestic and these loads are inductive in nature and draws lagging current due to which power losses occurred in the power distribution system. To minimize the reactive impact of the load and power losses in the system, network reconfiguration, capacitor placement and superior optimization methods are used [1].

Capacitor provides leading current to the system which minimizes the lagging current impact of the load in the system. As a result, system power factor improves, voltage profile enhanced and power losses minimized. These factors can be controlled and improved by optimally placing the capacitors in the power system. Significant research has been done in this manner which provide healthy outcomes in the form of cost saving for power suppliers and customers at a same time.

Several researchers worked on capacitor placement using different power tools like; MATLAB[2], PYTHON [3] and ETAP [4] . Most of the researchers worked on Matlab to resolve this problem. They used several algorithms like; genetic algorithm [5], particle sarm optimization [6], direct search, ant colony [7], artificial bee colony [8], fire fly [9], honey bee [10], harmony search [11], cuckoo search [12] algorithm and test systems to validate their results on power system like; IEEE or local bus system. In this paper ETAP 
software is utilized to optimally loacate the capacitor and its sizing in the distribution system, so work done on ETAP relevant literature is discussed below.

S. Neelima and P. S. Subramanyam [13] presented an OCP problem for a IEEE 69 bus system. Their research based upon two stages firstly they determine the potential location for capacitor by dimension reducing load flow method then on the second stage they use GA algorithm for optimal sizing of the capacitor in the system. They used ETAP software for the voltage profile enhancement and reduction in power losses of the IEEE system.

Every power system has active and reactive components. Capacitor is a common source which is used to minimize reactive element of the power system. Roy billinton test system (RBTS) 60 bus distribution system is considered in [14] for the capacitor allocation and rating. The objective is to minimize the voltage drop and power losses of the system.

In [15] they proposed a solution methodology for capacitor placement at Tehran Metro line-2 power system with the objective function of voltage profile enhancement, improvement of power factor and minimization of losses. They have used ETAP software for the real time implementation of power system. Interconnected distorted power system considered for the optimal capacitor placement and sizing with voltage, no of capacitor banks and total harmonic distortion constraints. The objective function is to minimize the supply cost with the minimum number of capacitors. For the problem solution and evaluation IEEE 30 bus system is selected [16].

To show the effectiveness of the proposed technique local $22 \mathrm{KV}$ distribution station is modelled and evaluated for the installation and sizing of capacitors under the short circuit interruption conditions [17]. They concluded that by proper placing and rating the capacitors in the distribution system short circuit interruption incident can be minimized and system maintenance cost can be reduced.

Local 132KV operating grid station is modelled and grid is modelled for the Radial, loop and interconnected configuration and tested over the ETAP software. To demonstrate the efficiency of proposed algorithm for the minimization of objective function a comparative analysis is done between radial, loop and interconnected power system and results conclude that loop and interconnected system performs better as compare to radial network for linear loads after installing capacitor banks [18].

A. kumar and R. S. Bhatia [19] exhibited the problem formulation for reactive compensating device placement and rating for a IEEE 10 bus radial distribution network. They modelled the network on ETAP using data and implies genetic algorithm for capacitor placement in the distribution network, to achieve cost effective system having improved voltage and low power losses.

In [20] Southern California Edison power system operating on $12.47 \mathrm{KV}$ is modelled using ETAP and openDSS softwares. Capacitor placement for the reactive compensation and losses minimization is done in the presence of distorted photo voltic generation. A comparative study is presented for the capacitor placement problem with cost minimization objective function under available load curves.

This paper presents the Optimal capacitor placement and sizing problem solution for IEEE 4bus system, 33 bus system and NTDC 220KV real time grid station using genetic algorithm. For this purpose, in section 2, branch current flow is tabulated with reactive compensation limitations. In section 3 , system modelling is done for IEEE 4, 33 and NTDC $220 \mathrm{kV}$ real time grid and cost minimization objective function with system limitations are defined. In section 4, results are discussed in the form of voltage profile, power losses, and annual net profit. In section 5, conculsion of this paper is given and in the appendix data is tabulated for the power systems under test.

\section{PROBLEM FORMULATION}

The Aim of this paper is to minimize the cost function while determining the OCP for the system voltage profile enhancement, power losses minimization and power factor improvement. Current flow in a branch i,k can be expressed as relation between branch active and reactive power with respect to node voltage.

$$
I_{i k}=\frac{P_{i k}-j Q_{i k}}{V_{i}}
$$

The net loss of power in a feeder can be stated as:

$$
T P L=\sum_{i k=1}^{n}\left|I_{i k}\right|^{2} R_{i k}
$$

Total power losses can also be formulated in the form of active and reactive component.

$T P L=T P L^{a}+T P L^{r}$ 


$$
T P L=\sum_{i k=1}^{n}\left|I_{i k}{ }^{a}\right|^{2} R_{i k}+\sum_{i k=1}^{n}\left|I_{i k}{ }^{r}\right|^{2} R_{i k}
$$

As capacitor draw leading current which make impact to the relevant branch only so branch(i,k) new current can be given as:

$$
\begin{aligned}
& I_{r_{i k}}{ }^{\text {new }}=I_{i k}{ }^{r}+D_{i k} I_{i k}{ }^{c} \\
& \text { Where }\left\{\begin{array}{c}
D_{i k=1, \text { if } \text { branch }(i, k) \in \alpha} \\
D_{i k=0, \text { otherwise }}
\end{array}\right.
\end{aligned}
$$

Power losses after capacitor placement can be stated as:

$$
T P L_{r}{ }^{T}=\sum_{i k=1}^{n}\left|I_{i k}{ }^{r}+D_{i k} I_{c}\right|^{2} R_{i k}
$$

Here total loss saving can be placed by subtracting (6) and (5).

$$
T L S=\sum_{i k=1}^{n}\left(2 D_{i k} I_{i k}^{r}+D_{i k} I_{c}^{2}\right) R_{i k}
$$
expressed as:

By derivating the above equation w.r.t Ic the maximum saving current drawn by the capacitor can be

$$
0=\sum_{i k=1}^{n}\left(D_{i k} I_{i k}^{r}+D_{i k} I_{c}\right) R_{i k}
$$

So the capacitor current for the maximum cost saving is finalized as:

$$
I_{c}=\frac{-\sum_{i k \in \alpha}^{n}\left(I_{i k}^{r}\right) R_{i k}}{\sum_{i k \in \alpha}^{n} R_{i k}}
$$

While sizing the capacitors it is very necessary to meet system reactive power constraints, for this size of capacitor for a relevant bus can be expressed as:

$$
Q_{c}=V_{m} I_{c}
$$

The reactive power injected by capacitor can be limited by:

$Q_{c j}{ }^{\min } \leq Q_{c j} \leq Q_{c j}^{\max }$

While reactive power injected should be less then load reactive power.

$$
Q_{c}^{\text {Total }} \leq Q_{L}^{\text {Total }}
$$

\section{SYSTEM MODELING AND OCP}

As energy demand in the world is increasing day by day as a result power losses are also increasing simultaneously. So it is the time to take suitable measures to minimize these losses and stabilize the power system. Capacitor switching is a common practice for this purpose. Capacitor switching produces transients in the system, so grid equipment should be capable to handle these switching transients so that grid system could be stabilized [21]. In this paper three power system i-e, IEEE 4, IEEE 33 bus system and NTDC $220 \mathrm{KV}$ real time grid station is taken for the OCP problem having system cost minimization objective function.

\subsection{IEEE 4 Bus System}

To minimize the power losses of the system IEEE 4 bus system is being modelled and evaluated using ETAP software. This system consists of a single utility supply operating at $12.47 \mathrm{KV}$ which is delivering the power towards the load by two transmission lines. 6000KVA Y-Y transformer is used to stabilize and transfer the power by stepping down the voltage at $4.16 \mathrm{KV}$. load demand is $5999.6 \mathrm{KVA}$ all grid elements are interconnected with each other by 4 Bus-bars. For the OCP problem stated system is evaluated using load flow method. Through this method it is found that bus 3 and 4 have high voltage drop and they are 
violating the voltage constraints. So these two buses are nominated for the OCP. Single line diagram of IEEE 4 bus system as shown in Figure 1.

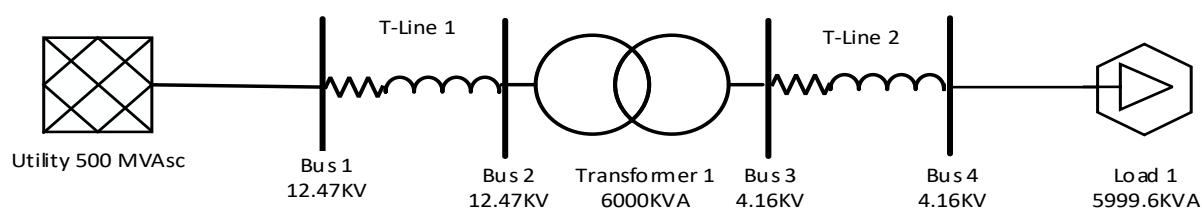

Figure 1. Single line diagram of IEEE 4 bus system [22]

\subsection{IEEE 33 Bus System}

To minimize the power losses of the IEEE 33 bus system is being modelled and evaluated using ETAP software. This system consists of a single utility supply operating at $12.66 \mathrm{KV}$ which is delivering the power towards the load by thirty-two transmission lines. load demand is $4548.56 \mathrm{kVA}$ all grid elements are interconnected with each other by 33 Bus-bars. For the OCP problem first system is evaluated using load flow method. Through this method it is found that bus 30 have high voltage drop and other fifteen buses are violating the voltage constraints. So these sixteen buses are nominated for the OCP. Single line diagram of IEEE 33 bus system as shown in Figure 2.

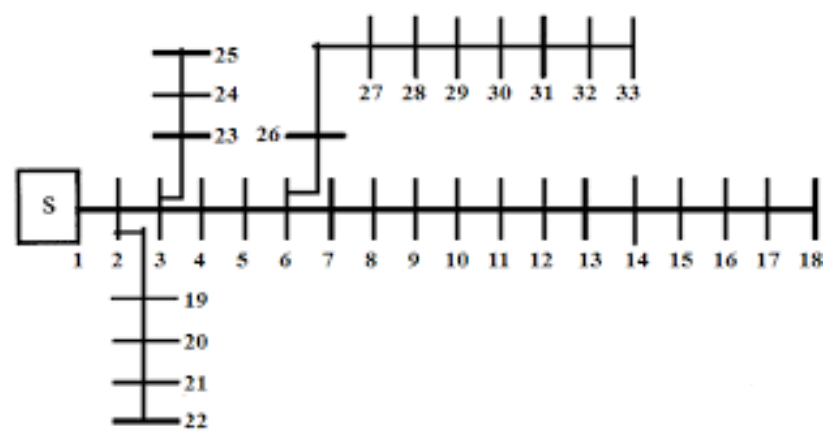

Figure 2. Single line diagram of IEEE 33 bus system [23]

\subsection{NTDC 220KV Grid System}

For the reduction of power losses in the system NTDC $220 \mathrm{kV}$ grid system is being demonstrated and assessed using ETAP software. This system consists of a four utility supplies operating at 220KV and delivering the power towards the load end by using stepping down the operating voltage two time firstly $220 / 132 \mathrm{KV}$ then $132 / 11 \mathrm{KV}$. One and a half circuit breaker scheme is used to interconnect $220 \mathrm{KV}$ utility incoming lines with the grid system. Four transformers with delta to delta connection are used to step down the operating voltage from 220/132KV with 100-125MVA rating. Here again double Bus-bar is used for safety and continuity of the system. Two transformers are used with delta to star connection are used to stepdown the operating voltage from $132 / 11 \mathrm{KV}$ with $20-25 \mathrm{MVA}$ rating. At $11 \mathrm{KV}$ there are two Bus-bars 11 1 and 11-2. 11-1 is delivering the power to four distribution feeders and 11-2 is delivering the power to five distribution feeders. Each feeder has different load and different feeder length. Both Bus-bars 11-1 and 11-2 are interconnected with each other by a tie-switch so that load can be shifted on the other transformer in case of overloading.

Firstly, grid system is assessed for the capacitor placement by using load flow technique. Through this technique it is discovered that bus 11-1 and 11-2 facing high voltage drop and they are crossing the boundaries of the voltage constraints, so these two buses are nominated for the OCP. To enhance the voltage profile, improve the power factor and minimize the system power losses in all three modelled systems OCP is done by using GA technique in ETAP software with the system cost minimization objective function. In 1975 Holland initially anticipated GA technique [12]. GA is a robust technique which simulates the transformative procedure in the nature and it is established on selection of the nature and best survival rule in numerous manners GA technique differs from other existing heuristic techniques. The most influential discrepancy between others techniques and GA is that other works on single solution method while GA 
mechanism depends upon the population of possible solutions in its iteration. One more discrepancy of GA technique is that it doesn't work on deterministic approach its works on stochastic approach. While using this GA technique the objective function can be expressed as:

$$
\begin{aligned}
& \text { MinObj }=\sum_{i=1}^{N_{\text {bus }}}\left(x_{i} C_{0 i}+Q_{c i} C_{1 i}+B_{i} C_{2 i} T\right)+C_{2} \sum_{i=1}^{N_{\text {load }}}\left(T_{l} P_{L}^{l}\right) \\
& V_{\text {min }} \leq V \leq V_{\text {min }} \\
& P f_{\text {min }} \leq P f \leq P f_{\text {max }}
\end{aligned}
$$

Cost of any power system cannot be minimized without considering the following factors i-e buying cost of the capacitor banks, placement cost of the capacitor banks, functioning cost of the capacitors and active power losses cost of the system. While minimizing the cost function is necessary to consider the voltage and power factor constraints. So, bus voltages and system power factor can be limitized as and Single line diagram of 220KV grid system as shown in Figure 3.

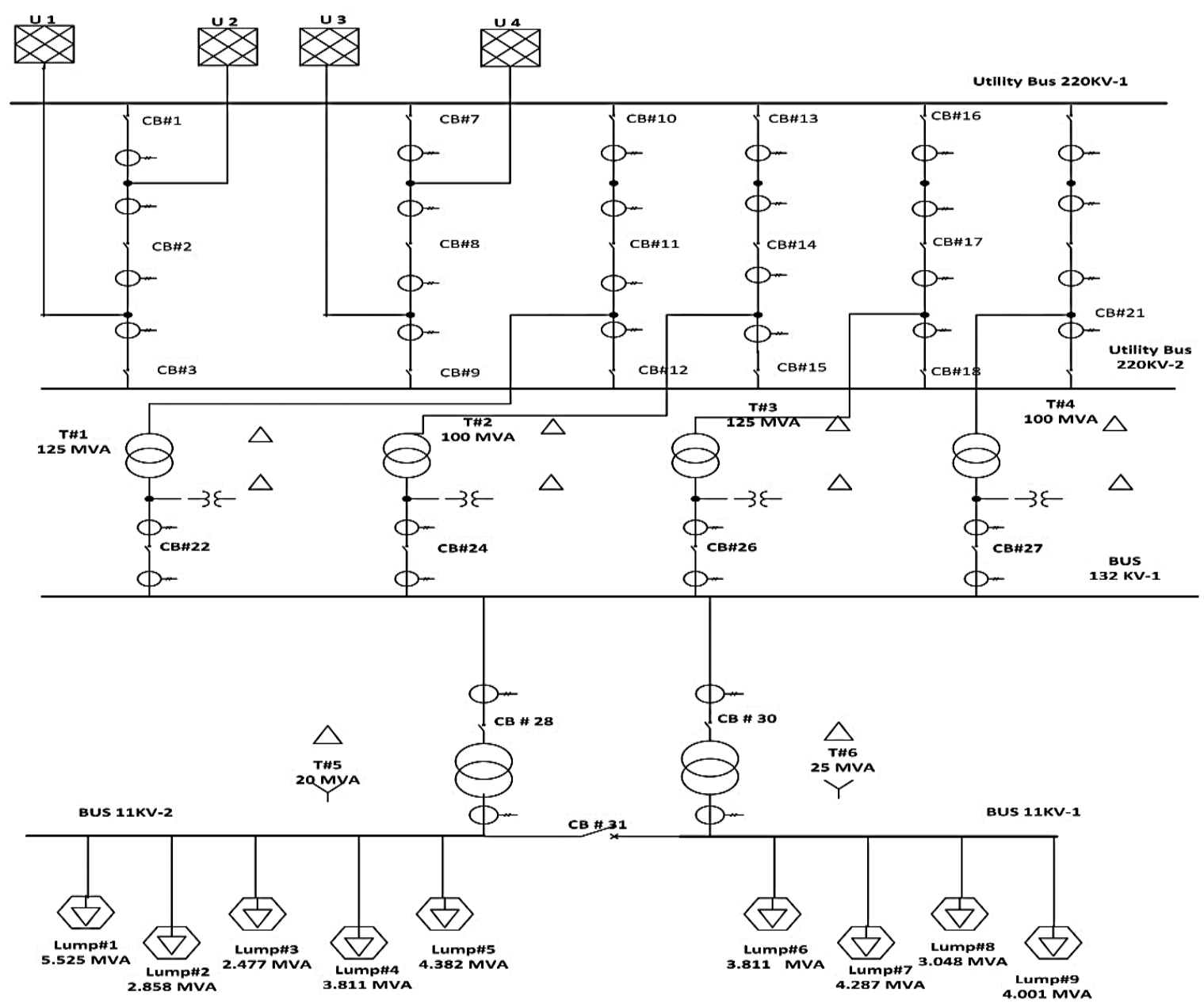

Figure 3. Single line diagram of 220KV grid system [11]

\section{RESULTS AND DISCUSSION}

Provide IEEE 4,33 bus system and NTDC 220KV grid stations are modelled on ETAP using real time data which is stated in Appendix Tables 6, 8 and 10. From Table 6 it can be seen that IEEE 4 bus system utility is operating at $5869.3 \mathrm{~kW}$ with $3863.6 \mathrm{kVar}$ draining 563.5 ampere with 0.84 power factor and load is behaving as $100 \%$ inductive load having $5399.6 \mathrm{~kW}$ and $2615.2 \mathrm{kVar}$ and operating on 832.7 ampere with 
0.90 power factor. It can be noted from Table 1 that branches are having $469.7 \mathrm{~kW}$ and $1248.4 \mathrm{kV}$ ar loss and branches having maximum voltage drop of 10.23 percent. Before capacitor placement minimum voltage is 84.4 percent which is improved up to 96 percent after placing 22 capacitors having $4400 \mathrm{kVar}$ rating which provides 103965.2\$ system cost saving per year. Capacitor rating, number of banks, purchase, installation and operating cost details are given in Table 7. IEEE 4 Bus System Voltage Profile and Placed Capacitor Rating and IEEE 33 Bus System Branch Losses as shown in Tables 2 and 3.

Table 1. IEEE 4 Bus System Branch Losses

\begin{tabular}{ccccccc}
\hline Sr No. & \multicolumn{3}{c}{ Before OCP } & \multicolumn{3}{c}{ After OCP } \\
\cline { 2 - 7 } & Loss & Loss & $\%$ & Loss & Loss & $\%$ \\
& $\mathrm{~kW}$ & $\mathrm{kVar}$ & Voltage Drop & $\mathrm{kW}$ & $\mathrm{kVar}$ & Voltage Drop \\
L1 & 32.5 & 66.1 & 0.97 & 23.9 & 48.7 & 0.32 \\
$\mathrm{~T} 1$ & 72.6 & 435 & 4.43 & 53.6 & 322 & 0.09 \\
L2 & 364 & 747 & 10.23 & 262 & 537 & 3.46 \\
\hline
\end{tabular}

Table 2. IEEE 4 Bus System Voltage Profile and Placed Capacitor Rating

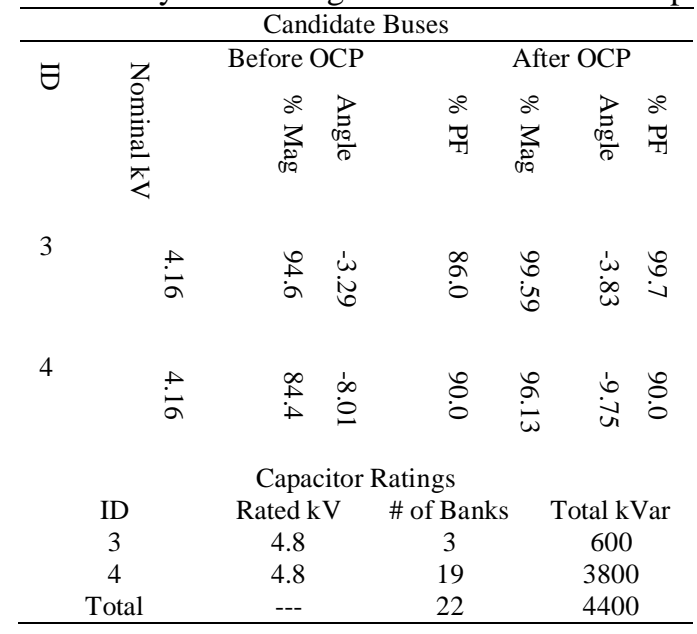

Table 3. IEEE 33 Bus System Branch Losses

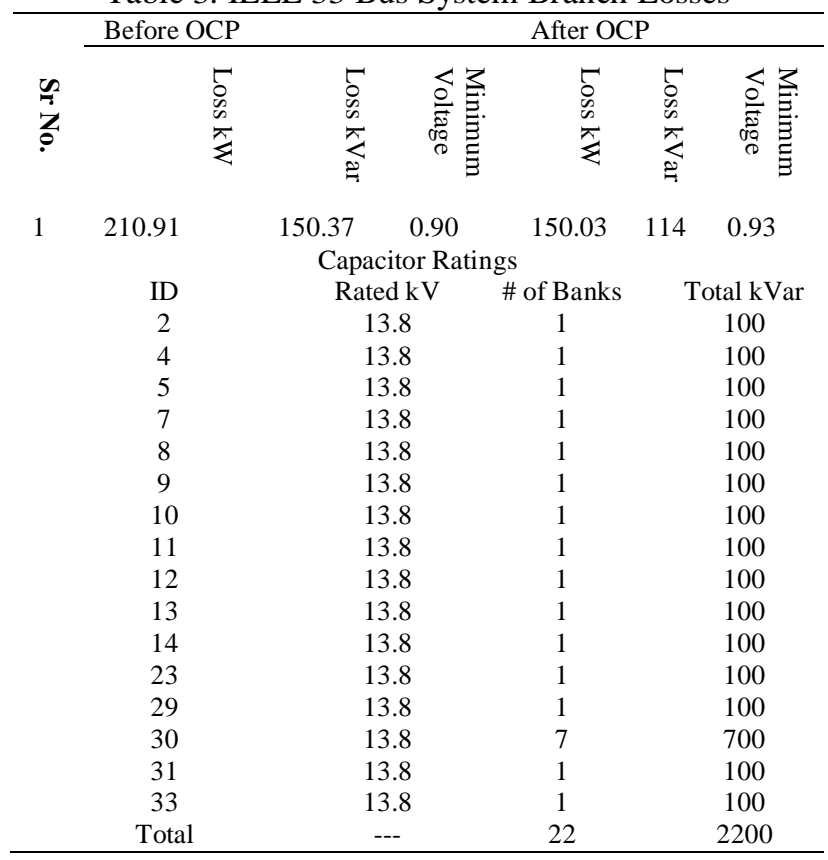


From Table 8 it can be seen that IEEE 33 bus system utility is operating at 2972kW with 1839kVar draining 296.3 ampere with 0.85 power factor and load is behaving as $100 \%$ inductive load having $2970 \mathrm{~kW}$ and $1838 \mathrm{kVar}$. It can be noted from Table 3 that before capacitor placement branches are having $210.91 \mathrm{~kW}$ and $150.37 \mathrm{kVar}$ loss and branches having minimum voltage of 90 percent which is improved up to 93 percent after placing 22 capacitors having $2200 \mathrm{kVar}$ rating which provides $1887.84 \$$ system cost saving per year. Capacitor rating, number of banks, purchase, installation and operating cost details are given in Table 9. IEEE 4 Bus System Profit Profile, IEEE 33 Bus voltage profile with and without OCP, IEEE 33 Bus system profit profile as shown in Figures 4 till $6.220 \mathrm{kV}$ grid system branch losses and $220 \mathrm{kV}$ grid system voltage profile and placed capacitor rating as shown in Tables 4 and 5.

From Table 10 it can be seen that NTDC $220 \mathrm{kV}$ grid system utility is operating at $27944 \mathrm{~kW}$ with $20832 \mathrm{kVar}$ draining 91.48 ampere with 0.80 power factor and load is behaving as $70 \%$ inductive and $30 \%$ static load having $27826 \mathrm{~kW}$ and $18130 \mathrm{kVar}$. It can be noted from Table 4 that before capacitor placement branches are having $112.27 \mathrm{~kW}$ and $2391.6 \mathrm{kVar}$ loss and branches having minimum voltage of 95.31 percent which is improved up to 96.96 after placing 32 capacitors having $9600 \mathrm{kVar}$ rating which provides $45889.85 \$$ system cost saving per year. Capacitor rating, number of banks, purchase, installation and operating cost details are given in Table 11. NTDC 220KV grid system profit profile as shown in Figure 7.

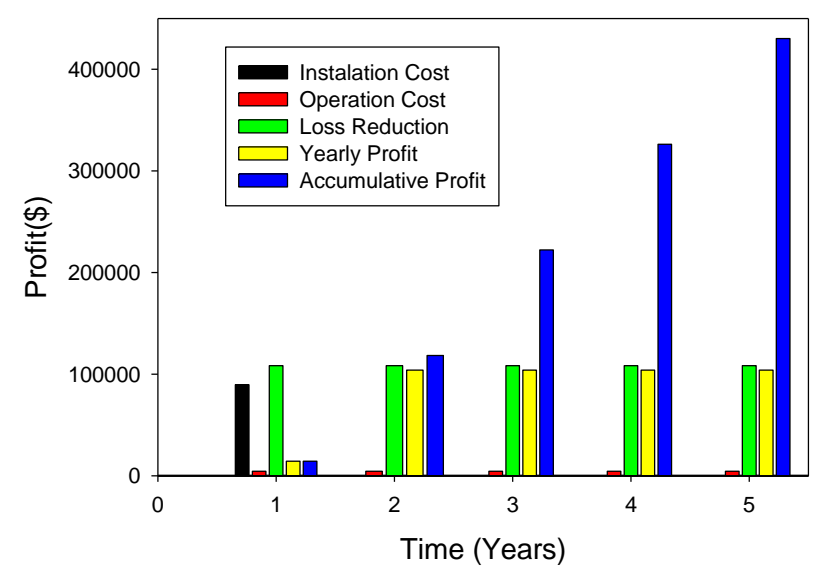

Figure 4. IEEE 4 Bus System Profit Profile

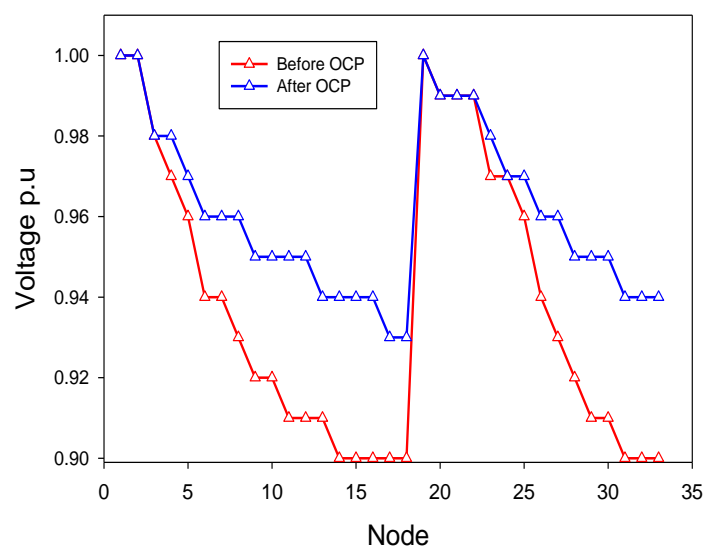

Figure 5. IEEE 33 Bus voltage profile with and without OCP

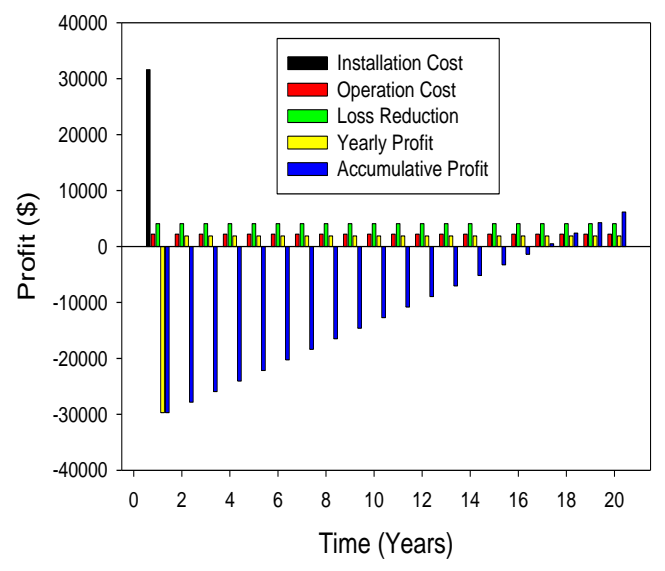

Figure 6. IEEE 33 Bus system profit profile 
Table 4. 220kV Grid System Branch Losses

\begin{tabular}{|c|c|c|c|c|c|c|}
\hline \multirow[b]{2}{*}{$\begin{array}{c}\mathrm{Sr} \\
\mathrm{No}\end{array}$} & \multicolumn{2}{|c|}{ Before OCP } & \multicolumn{3}{|c|}{ After OCP } & \multirow[b]{2}{*}{ 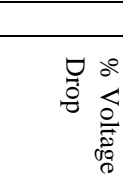 } \\
\hline & $\begin{array}{l}5 \\
0 \\
0 \\
⿱ 亠 幺 \\
\Sigma\end{array}$ & 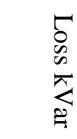 & 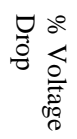 & $\begin{array}{l}5 \\
5 \\
\infty \\
\bar{n} \\
\sum\end{array}$ & $\begin{array}{l}5 \\
0 \\
\frac{0}{\pi} \\
\sum_{2} \\
\cong\end{array}$ & \\
\hline $\mathrm{T} 1$ & 43.9 & 1198 & 3.92 & 30.87 & 842.9 & 1.84 \\
\hline $\mathrm{T} 2$ & 56.9 & 1137 & 4.15 & 47.54 & 950.7 & 2.74 \\
\hline L1 & 1.15 & 5.64 & 0.08 & 1.13 & 5.52 & 0.07 \\
\hline L2 & 2.24 & 10.97 & 0.28 & 2.19 & 10.73 & 0.28 \\
\hline L3 & 0.33 & 1.63 & 0.05 & 0.324 & 1.59 & 0.05 \\
\hline $\mathrm{L} 4$ & 2.65 & 12.8 & 0.22 & 2.59 & 12.55 & 0.21 \\
\hline L5 & 0.57 & 2.8 & 0.05 & 0.56 & 2.74 & 0.05 \\
\hline L6 & 1.01 & 4.96 & 0.09 & 0.99 & 4.89 & 0.09 \\
\hline L7 & 1.33 & 6.54 & 0.1 & 1.31 & 6.45 & 0.1 \\
\hline L8 & 1.45 & 7.13 & 0.15 & 1.43 & 7.03 & 0.15 \\
\hline L9 & 0.80 & 3.91 & 0.06 & 0.786 & 3.85 & 0.06 \\
\hline
\end{tabular}

Table 5. 220kV Grid System Voltage Profile and Placed Capacitor Rating

\begin{tabular}{|c|c|c|c|c|c|c|c|}
\hline \multicolumn{8}{|c|}{ Candidate Buses } \\
\hline \multirow[t]{2}{*}{ ID } & & \multicolumn{2}{|c|}{ Before OCP } & \multicolumn{4}{|c|}{ After OCP } \\
\hline & . & $\underset{\substack{0 \\
\text { वat }}}{3}$ & 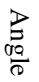 & $\frac{d}{T}$ & $\underset{\substack{3 \\
\text { वa }}}{3}$ & 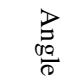 & $\frac{\partial}{T}$ \\
\hline 士 & 二 & 茪 & $\underset{\infty}{\dot{\omega}}$ & 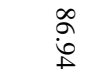 & 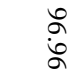 & نه & $\underset{\infty}{\stackrel{\infty}{\infty}}$ \\
\hline Б゙ & 二 & $\begin{array}{l}\text { ü } \\
\text { un } \\
\text { w }\end{array}$ & $\dot{\omega}$ & $\begin{array}{l}\infty \\
\stackrel{\infty}{0}\end{array}$ & $\begin{array}{l}\stackrel{+}{+} \\
\infty \\
\alpha\end{array}$ & 山ُ & $\begin{array}{l}0 \\
\text { ب } \\
\pm\end{array}$ \\
\hline \multicolumn{8}{|c|}{ Capacitor Ratings } \\
\hline & $\mathrm{D}$ & Rated kV & & \# of Ban & & Total & \\
\hline & -1 & 12.47 & & 10 & & 30 & \\
\hline & -2 & 12.47 & & 22 & & 66 & \\
\hline & tal & --- & & 32 & & 96 & \\
\hline
\end{tabular}

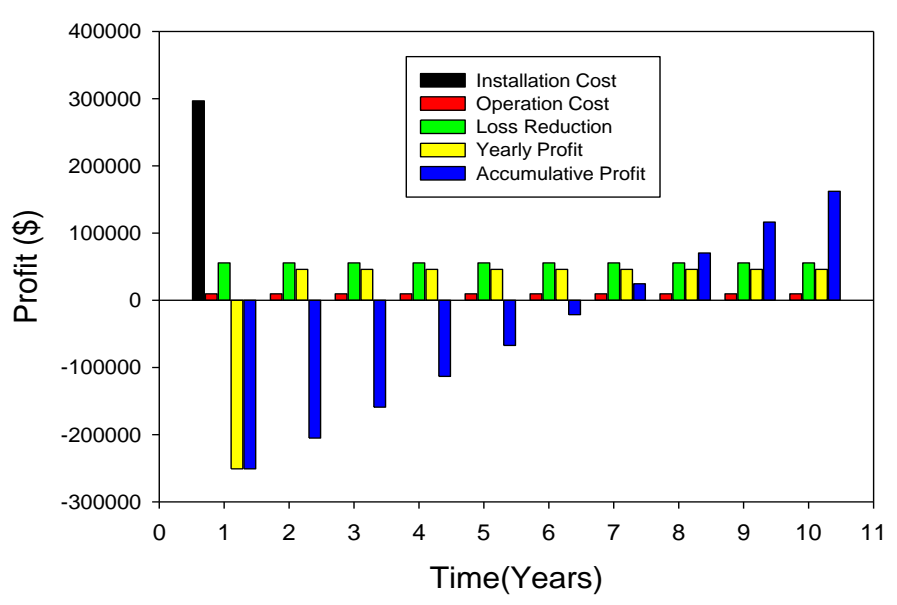

Figure 7. NTDC 220KV grid system profit profile

\section{CONCLUSION}

Optimal capacitor placement successfully implemented on IEEE 4bus,33bus and 220kV NTDC grid stations using GA algorithm on ETAP software. It can be seen that OCP helps to improve the voltage profile, enhance the power factor and minimize the power losses of the evaluated systems. The results show, that after placing the capacitors optimally using ETAP software all considered power systems voltage profiles has been improved, power factors has been enhanced and power losses has been minimized as a result, cost of power systems has been minimized and inversely net profit increased.

\section{ACKNOWLEDGEMENT}

I would like to acknowledge UniKL for sponsoring me through STRG research grant.

\section{REFERENCES}

[1] M. J. Tahir, I. A. Latiff, M. Alam, and M. Mazliham, "Network Reconfiguration Using Modified Particle Swarm Algorithm," in 2018 2nd International Conference on Smart Sensors and Application (ICSSA), 2018, pp. 1-5.

[2] https://www.mathworks.com/

[3] https://www.python.org/

[4] https://etap.com/

[5] G. Levitin, A. Kalyuzhny, A. Shenkman, and M. Chertkov, "Optimal capacitor allocation in distribution systems using a genetic algorithm and a fast energy loss computation technique," IEEE Transactions on Power Delivery, vol. 15 , pp. 623-628, 2000. 
[6] X.-m. Yu, X.-y. Xiong, and Y.-w. Wu, "A PSO-based approach to optimal capacitor placement with harmonic distortion consideration," Electric Power Systems Research, vol. 71, pp. 27-33, 2004.

[7] R. Annaluru, S. Das, and A. Pahwa, "Multi-level ant colony algorithm for optimal placement of capacitors in distribution systems," in Proceedings of the 2004 Congress on Evolutionary Computation (IEEE Cat. No. 04TH8753), 2004, pp. 1932-1937.

[8] A. K. Sarma and K. M. Rafi, "Optimal capacitor placement in radial distribution systems using artificial bee colony (abc) algorithm," Innovative Systems Design and Engineering, vol. 2, pp. 177-185, 2011.

[9] A. K. Fard and T. Niknam, "Optimal stochastic capacitor placement problem from the reliability and cost views using firefly algorithm," IET Science, Measurement \& Technology, vol. 8, pp. 260-269, 2014.

[10] S. A. Taher and R. Bagherpour, "A new approach for optimal capacitor placement and sizing in unbalanced distorted distribution systems using hybrid honey bee colony algorithm," International Journal of Electrical Power \& Energy Systems, vol. 49, pp. 430-448, 2013.

[11] R. Sirjani, A. Mohamed, and H. Shareef, "Optimal allocation of shunt Var compensators in power systems using a novel global harmony search algorithm," International Journal of Electrical Power \& Energy Systems, vol. 43, pp. $562-572,2012$.

[12] A. A. El-Fergany and A. Y. Abdelaziz, "Cuckoo search-based algorithm for optimal shunt capacitors allocations in distribution networks," Electric Power Components and Systems, vol. 41, pp. 1567-1581, 2013.

[13] S. Neelima and P. Subramanyam, "Optimal Capacitors Placement In Distribution Networks Using Genetic Algorithm: A Dimension Reducing Approach," Journal of Theoretical \& Applied Information Technology, vol. 30, 2011.

[14] P. Sarkar, S. Chatterjee, and S. Ray, "Optimal placement of capacitor for voltage support and minimizing overall cost in radial distribution system," International Journal of Computer Applications, vol. 65, 2013.

[15] M. Ghiasi and J. Olamaei, "Optimal capacitor placement to minimizing cost and power loss in Tehran metro power distribution system using ETAP (A case study)," Complexity, vol. 21, pp. 483-493, 2016.

[16] A. G. Sayed and H. K. Youssef, "Optimal sizing of fixed capacitor banks placed on a distorted interconnected distribution networks by genetic algorithms," in 2008 IEEE Region 8 International Conference on Computational Technologies in Electrical and Electronics Engineering, 2008, pp. 180-185.

[17] M. Pranitha and K. V. Chandrakala, "Optimal capacitor placement based improved reliability assessment of a distribution system," in 2017 International Conference on Intelligent Computing and Control (I2C2), 2017, pp. 1-6.

[18] P. Chopade and M. Bikdash, "Minimizing cost and power loss by optimal placement of capacitor using ETAP," in 2011 IEEE 43rd Southeastern Symposium on System Theory, 2011, pp. 24-29.

[19] A. Kumar and R. Bhatia, "Optimal capacitor placement in radial distribution system," in 2014 IEEE 6th India International Conference on Power Electronics (IICPE), 2014, pp. 1-6.

[20] C. B. Ferreira and D. Gebbran, "Simulation and Analysis of Reactive Power Compensation Methods in Presence of Solar Distributed Generation and Development of Optimal Capacitor Placement and Sizing," UC Irvine, 2017.

[21] M. Tahir, I. Latiff, M. Alam, and M. Mazliham, "Transient Stability Analysis: Evaluation of IEEE 9 Bus System Under Line Fault Conditions," Journal of Engineering Technology, vol. 5, pp. 54-58, 2017.

[22] sites.ieee.org/pes-testfeeders/resources/.

[23] M. J. Tahir, B. A. Bakar, M. Alam, and M. Mazliham, "Distribution System Power Losses Minimization Using Network Reconfiguration," International Journal of Integrated Engineering, vol. 10, 2018.

[24] D. Whitley, "A genetic algorithm tutorial," Statistics and computing, vol. 4, pp. 65-85, 1994.

[25] M. Tahir, I. Latiff, M. Gul, M. Alam, and M. Mazliham, "Symmetrical and Asymmetrical Fault Currents: Evaluation to Enhance the Performance of 220KV Grid Station," Journal of Telecommunication, Electronic and Computer Engineering (JTEC), vol. 10, pp. 147-152, 2018.

\section{BIOGRAPHIES OF AUTHORS}

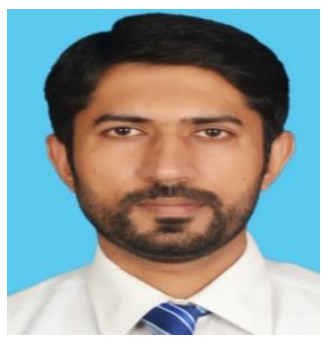

Muhammad Junaid Tahir, recently pursing PhD from Universiti Kuala Lumpur in Electrical and Electronic Engineering. He received his B.Sc and M.Sc engineering degree from University of Lahore, punjab, Pakistan in 2008 and 2015 respectively. His research interest includes the area of Power System, modelling, analysis, and Optimization. 


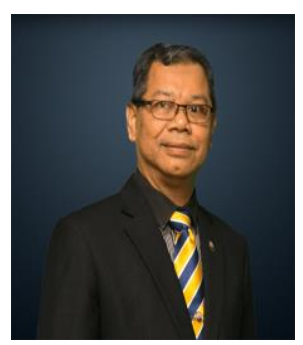

Badri Abu Bakar received his $\mathrm{PhD}$ degree in Industrial Automation from Bradford University, UK on 4 Dec 1993. He did his MSc engineering in Control \& Digital System from Aston University, Birmingham, UK in 1983 and B.Sc in Electrical \& Electronics from Strathclyde University, Glasgow in 1979. He is working as Professor in Electrical section BMI, UniKL and Project Leader Research Cluster - Microelectronics.

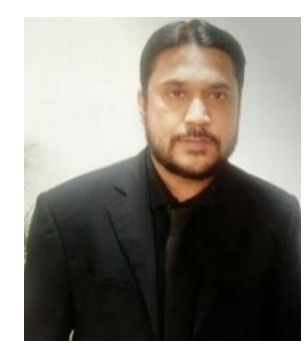

Dr. Muhammad Mansoor Alam holds $\mathrm{PhD}$ degree in Computer Engineering, PhD Electrical and Electronic Engineering, M.E. Systems Engineering and M.Sc. Computer Science. He is an active researcher in the field of Telecommunication and Network. He has authored more than 60 research articles published in ISI indexed journals, as book chapters and in peer reviewed conferences. He is also an author of the book "Study guide of Network Security" copyrighted by Open University Malaysia and Open University Hong Kong. Dr. Muhammad is also an active reviewer of ISI indexed journal "Pertanika journal of science and technology (JST)".

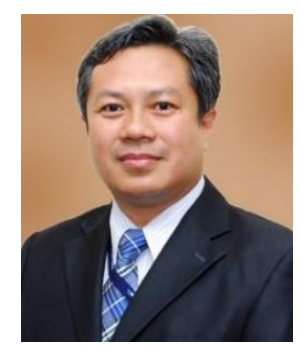

Mazliham Mohd Su'ud Received his PhD from Université de La Rochelle in Computer Engineering in 2007 and Master's degree in Electrical and Electronics Engineering from University of Montpellier in 1993 and Since 2013 he is working as President/CEO of Universiti Kuala Lumpur Malaysia.

\section{Appendix}

Table 6. IEEE 4 Bus System Load Data

\begin{tabular}{|c|c|c|c|c|c|c|}
\hline Sr No. & \multicolumn{2}{|c|}{ Utility kW } & \multicolumn{2}{|c|}{ Utility kVar } & Utility \%PF & Utility Amp \\
\hline \multicolumn{7}{|c|}{ AT Utility $12.47 \mathrm{KV}$} \\
\hline 1 & \multicolumn{2}{|l|}{5869.3} & \multicolumn{2}{|l|}{3863.6} & 83.53 & 563.5 \\
\hline \multirow[t]{2}{*}{ Sr No. } & \multicolumn{2}{|c|}{ Motor Load (100\%) } & \multicolumn{2}{|c|}{ Static Load (0\%) } & Load & Load \\
\hline & Load kW & Load kVar & Load kW & Load kVar & $\% \mathrm{PF}$ & Amp \\
\hline 1 & 5399.6 & 2615.2 & 0.00 & 0.00 & 90 & 832.7 \\
\hline
\end{tabular}

Table 7. Capacitor Info for IEEE 4 Bus System

\begin{tabular}{cllllll}
\hline Sr No. & $\begin{array}{l}\text { Max } \\
\mathrm{kV}\end{array}$ & $\begin{array}{l}\text { Bank Size } \\
(\mathrm{kVar})\end{array}$ & $\begin{array}{l}\text { Max Number } \\
\text { of Banks }\end{array}$ & $\begin{array}{l}\text { Purchase } \\
(\$ / \mathrm{kVar})\end{array}$ & $\begin{array}{l}\text { Install } \\
(\$)\end{array}$ & $\begin{array}{l}\text { Operating } \\
(\$ / \text { Bank Yr })\end{array}$ \\
\hline 1 & 4.8 & 200 & 20 & 20 & 800 & 200 \\
\hline
\end{tabular}

Table 8. IEEE 33 Bus System Load Data

\begin{tabular}{|c|c|c|c|c|c|c|}
\hline Sr No & \multicolumn{2}{|l|}{ Utility kW } & \multicolumn{2}{|c|}{ Utility kVar } & Utility \%PF & Utility Amp \\
\hline \multicolumn{7}{|c|}{ AT Utility $12.66 \mathrm{KV}$} \\
\hline 1 & 3180.91 & & 1988.37 & & 84.80 & 296.3 \\
\hline \multirow[t]{2}{*}{ Sr No. } & \multicolumn{2}{|c|}{ Motor Load (100\%) } & \multicolumn{2}{|c|}{ Static Load $(0 \%)$} & Load & Load \\
\hline & Load kW & $\begin{array}{l}\text { Load } \\
\mathrm{kVar}\end{array}$ & Load kW & $\begin{array}{l}\text { Load } \\
\mathrm{kVar}\end{array}$ & $\% \mathrm{PF}$ & Amp \\
\hline 1 & 80 & 48 & 0.00 & 0.00 & 85.75 & 4.255 \\
\hline 2 & 72 & 32 & 0.00 & 0.00 & 91.38 & 3.594 \\
\hline 3 & 96 & 64 & 0.00 & 0.00 & 83.21 & 5.261 \\
\hline 4 & 48 & 24 & 0.00 & 0.00 & 89.44 & 2.447 \\
\hline 5 & 48 & 16 & 0.00 & 0.00 & 94.87 & 2.307 \\
\hline 6 & 160 & 80 & 0.00 & 0.00 & 89.44 & 8.155 \\
\hline 7 & 160 & 80 & 0.00 & 0.00 & 89.44 & 8.154 \\
\hline 8 & 48 & 16 & 0.00 & 0.00 & 94.87 & 2.306 \\
\hline 9 & 48 & 16 & 0.00 & 0.00 & 94.87 & 2.306 \\
\hline 10 & 36 & 24 & 0.00 & 0.00 & 83.21 & 1.972 \\
\hline 11 & 48 & 28 & 0.00 & 0.00 & 86.38 & 2.533 \\
\hline
\end{tabular}




\begin{tabular}{lllllll}
12 & 48 & 28 & 0.00 & 0.00 & 86.38 & 2.533 \\
13 & 96 & 64 & 0.00 & 0.00 & 83.21 & 5.259 \\
14 & 48 & 8 & 0.00 & 0.00 & 98.64 & 2.218 \\
15 & 48 & 16 & 0.00 & 0.00 & 94.87 & 2.306 \\
16 & 48 & 16 & 0.00 & 0.00 & 94.87 & 2.306 \\
17 & 72 & 32 & 0.00 & 0.00 & 91.38 & 3.593 \\
18 & 72 & 32 & 0.00 & 0.00 & 91.38 & 3.593 \\
19 & 72 & 32 & 0.00 & 0.00 & 91.38 & 3.593 \\
20 & 72 & 32 & 0.00 & 0.00 & 91.38 & 3.593 \\
21 & 72 & 32 & 0.00 & 0.00 & 91.38 & 3.593 \\
22 & 72 & 40 & 0.00 & 0.00 & 87.42 & 3.755 \\
23 & 336 & 160 & 0.00 & 0.00 & 90.29 & 16.97 \\
24 & 336 & 160 & 0.00 & 0.00 & 90.29 & 16.97 \\
25 & 48 & 20 & 0.00 & 0.00 & 92.31 & 2.37 \\
26 & 48 & 20 & 0.00 & 0.00 & 92.31 & 2.37 \\
27 & 48 & 16 & 0.00 & 0.00 & 94.87 & 2.306 \\
28 & 96 & 56 & 0.00 & 0.00 & 86.38 & 5.066 \\
29 & 160 & 480 & 0.00 & 0.00 & 31.62 & 23.06 \\
30 & 120 & 56 & 0.00 & 0.00 & 90.62 & 6.036 \\
31 & 168 & 80 & 0.00 & 0.00 & 90.29 & 8.481 \\
32 & 48 & 32 & 0.00 & 0.00 & 83.21 & 2.629 \\
\hline
\end{tabular}

Table 9. Capacitor Info for IEEE 33bus Power System

\begin{tabular}{ccccccc}
\hline Sr No. & Max kV & $\begin{array}{c}\text { Bank Size } \\
(\mathrm{kVar})\end{array}$ & $\begin{array}{c}\text { Max Number } \\
\text { of Banks }\end{array}$ & $\begin{array}{c}\text { Purchase } \\
(\$ / \mathrm{kVar})\end{array}$ & $\begin{array}{c}\text { Install } \\
(\$)\end{array}$ & $\begin{array}{c}\text { Operating } \\
(\$ / \text { Bank Yr })\end{array}$ \\
\hline 1 & 13.8 & 100 & 10 & 10 & 600 & 100 \\
\hline
\end{tabular}

Table 10. NTDC Power System Load Data

\begin{tabular}{|c|c|c|c|c|c|c|}
\hline Sr No. & Utility kI & & \multicolumn{2}{|c|}{ Utility kVar } & Utility \% PF & Utility Amp \\
\hline \multicolumn{7}{|c|}{ AT Utility $220 \mathrm{KV}$} \\
\hline 1 & 6986.2 & & \multicolumn{2}{|l|}{5207.7} & 80.18 & 22.87 \\
\hline 2 & 6986.2 & & \multicolumn{2}{|l|}{5207.7} & 80.18 & 22.87 \\
\hline 3 & 6986.2 & & \multicolumn{2}{|l|}{5207.7} & 80.18 & 22.87 \\
\hline 4 & 6986.2 & & \multicolumn{2}{|l|}{5207.7} & 80.18 & 22.87 \\
\hline \multirow[t]{2}{*}{ Sr No. } & \multicolumn{2}{|c|}{ Motor Load (70\%) } & \multicolumn{2}{|c|}{ Static Load (30\%) } & Load & Load \\
\hline & Load kW & Load kVar & Load kW & Load kVar & $\% \mathrm{PF}$ & Amp \\
\hline \multicolumn{7}{|c|}{ AT 11-2 KV Bus-bar } \\
\hline 1 & 3133 & 2268 & 1343 & 972 & 81 & 290 \\
\hline 2 & 1620 & 1173 & 694.5 & 502.8 & 81 & 150 \\
\hline 3 & 1404 & 1017 & 601.9 & 435.8 & 81 & 130 \\
\hline 4 & 2485 & 1799 & 1065 & 770.9 & 81 & 230 \\
\hline 5 & 2161 & 1564 & 926.1 & 670.5 & 81 & 200 \\
\hline \multicolumn{7}{|c|}{ AT 11-1 KV Bus-bar } \\
\hline 6 & 2321 & 1315 & 994.7 & 563.7 & 87 & 200 \\
\hline 7 & 2611 & 1480 & 1119 & 634.1 & 87 & 225 \\
\hline 8 & 1856 & 1052 & 795.5 & 450.8 & 87 & 160 \\
\hline 9 & 2437 & 1381 & 1044 & 591.8 & 87 & 210 \\
\hline
\end{tabular}

Table 11. Capacitor Info for NTDC Power System

\begin{tabular}{ccccccc}
\hline Sr No. & Max kV & $\begin{array}{c}\text { Bank Size } \\
(\mathrm{kVar})\end{array}$ & $\begin{array}{c}\text { Max Number } \\
\text { of Banks }\end{array}$ & $\begin{array}{c}\text { Purchase } \\
(\$ / \mathrm{kVar})\end{array}$ & $\begin{array}{c}\text { Install } \\
(\$)\end{array}$ & $\begin{array}{c}\text { Operating } \\
(\$ / \mathrm{Bank} \mathrm{Yr})\end{array}$ \\
\hline 1 & 12.47 & 300 & 10 & 30 & 800 & 300 \\
\hline
\end{tabular}

